\title{
Diagnosis of Pneumocystis jirovecii pneumonia with serum cell- free DNA in non-HIV-infected immunocompromised patients
}

\author{
Dong Wang ${ }^{1, *}$, Yang Hu${ }^{1, *}$, Ting $\mathrm{Li}^{1}$, Heng-Mo Rong ${ }^{1}$ and Zhao-Hui Tong ${ }^{1}$ \\ ${ }^{1}$ Department of Respiratory Medicine and Critical Care Medicine, Beijing Institute of Respiratory Medicine and Beijing Chao- \\ Yang Hospital, Capital Medical University, Beijing, 100020, China \\ *These authors contributed equally to this work
}

Correspondence to: Zhao-Hui Tong, email: tongzhaohuicy@sina.com

Keywords: cell-free DNA, immunocompromised patients, Pneumocystis jirovecii, polymerase chain reaction, serum Received: March 29, $2017 \quad$ Accepted: May 08, $2017 \quad$ Published: May 20, 2017

Copyright: Wang et al. This is an open-access article distributed under the terms of the Creative Commons Attribution License 3.0 (CC BY 3.0), which permits unrestricted use, distribution, and reproduction in any medium, provided the original author and source are credited.

\section{ABSTRACT}

Conventional respiratory tract specimens, such as bronchoalveolar lavage (BAL) fluid and induced sputum for diagnosing Pneumocystis jirovecii pneumonia (PCP) in immunocompromised patients are difficult to obtain. Besides, bronchoscopy is an invasive procedure that carries the risk of causing rapidly progressive respiratory insufficiency. By contrast, serum cell-free DNA (cfDNA) is easy to obtain and has been proven useful in diagnosing cancer, pregnancy associated complications, parasite infection and sepsis. In this study, we performed quantitative polymerase chain reaction ( $q P C R$ ) to assess the diagnostic efficiency of using serum cfDNA, BAL fluid, and sputum DNA for PCP. Seventy-one patients (35 PCP patients and 36 nonPCP patients) were enrolled according to the clinical PCP diagnostic criteria. The sensitivity, specificity, positive predictive value, and negative predictive value of PCR using serum cfDNA were $68.6 \%$ (95\% CI, 50.7-83.1), 97.2\% (95\% CI, 85.5-99.9), 96.0\%, and 76.1\%, respectively. PCR using BAL fluid and sputum had a high sensitivity ( $97.1 \%$ and $91.4 \%$, respectively) but relatively low specificity $(86.1 \%$ and $86.1 \%$, respectively). The combination of the sputum PCR OR serum cfDNA PCR yielded a sensitivity of $\mathbf{9 7 . 1 \%}$. These results indicated that serum cfDNA might be a valuable method in PCP diagnosis.

\section{INTRODUCTION}

Pneumocystis Pneumonia (PCP) is a prevalent opportunistic fungus infection in immunocompromised patients, such as those with HIV infection, organ transplantation, malignancies, and connective tissue diseases [1-3]. Because of the use of highly active antiretroviral therapy, the incidence of PCP has decreased substantially in HIV-infected patients. However, in nonHIV-infected patients undergoing immunosuppressive therapies, whether with corticosteroids, monoclonal antibody or cytokine inhibitors, the morbidity and mortality of PCP in immunocompromised patients has remained high in recent years [4-7].

As an extracellular pathogen that is usually found in the alveolar cavity, Pneumocystis cannot readily be cultured in the laboratory. The gold standard method for the diagnosis of PCP mainly relies on microscopic detection for cysts in respiratory specimens; that is not sensitive enough [8]. Polymerase chain reaction (PCR) has been reported as a useful tool to assess Pneumocystis infection by detecting specimens from the respiratory tract. PCR on bronchoalveolar lavage (BAL) fluid and sputum is more sensitive than microscopic detection [9-11]. Nevertheless, in non-HIV PCP infected immunocompromised patients, operating bronchoscopy is usually difficult due to the underlying risk of rapidly progressive respiratory insufficiency [1]. Besides, patients with PCP often present with a non-productive cough, and induced sputum is not easy to obtain. Thus, a non-invasive method for Pneumocystis detection with high sensitivity and specificity is urgently required. 
Cell-free DNA (cfDNA) is the fragments of DNA found extracellularly in different body fluids and tissues, mainly in circulating blood. Recent studies of cfDNA detection on serum, urine, and saliva samples have revealed cfDNA to perform satisfactorily in the diagnosis of parasitic infections [12]. The objective of this study is to reveal the diagnostic value of serum cfDNA through the PCR method in PCP, when compared with GrocottGomori methenamine silver (GMS) staining, sputum, and BAL fluid PCR.

\section{RESULTS}

\section{Patient characteristics}

One hundred and five immunocompromised patients were recruited for this study from January 2015 to November 2016. Thirty-four of these were excluded due to either unavailable induced sputum or infeasible bronchoscopy procedure. As a result, 71 patients were enrolled; of these, 35 were clinically diagnosed with PCP while 36 had a non-PCP diagnosis (Figure 1). Among the 35 patients with clinical PCP, 18 were defined as PCP with positive GMS staining (10 with positive BAL fluid staining, 4 with positive sputum staining, and 4 with positive BAL fluid and sputum staining). Among the 36 non-PCP patients, 1 was diagnosed with pulmonary embolism, 1 was diagnosed with lung cancer, 2 were diagnosed with interstitial pneumonia, and 32 were diagnosed with as severe pneumonia ( 9 viral pneumonia, 17 bacterial pneumonia, and 6 fungal pneumonia, other than PCP).

The underlying diseases of the 71 patients could be divided into 3 groups: solid organ transplantation (5 with liver transplantation and 17 with kidney transplantation); malignancies ( 3 with leukemia, 2 with lymphoma, and 9 with solid tumors); immunosuppressed diseases $(n=35)$ (either experiencing some kind of immunodeficiency, or receiving either immunosuppressive, or cytotoxic medication) (Table 1).

\section{Diagnostic utility of GMS staining, BAL fluid, and sputum PCR}

When using defined diagnosis criteria, there were 18 PCP patients. The diagnostic consistency of PCR with GMS staining is summarized in Table 2. In the 18 defined PCP patients, BAL fluid PCR was positive in all patients, while sputum PCR was positive in 17 patients. When using GMS staining as the gold standard for diagnosing PCP, the sensitivity of PCR on BAL fluid and sputum was $100 \%$ (95\% CI, 81.5-100) and 94.4\% (95\% CI, 72.7-99.9),respectively, and the specificity of these 2 methods was $60.4 \%(95 \% \mathrm{CI}, 46.0-73.5)$ and $62.3 \%(95 \%$ CI, 47.9-75.2), respectively.

In the 35 clinical PCP patients, GMS staining, PCR on BAL fluid, and PCR on sputum was positive in 18, 34, and 32 cases, respectively (Table 3 ), When using clinical diagnosis criteria, the sensitivity of GMS, PCR on BAL fluid, and PCR on sputum was 51.4\% (95\% CI, 34.068.6), 97.1\% (95\% CI, 85.1-99.9), and 91.4\% (95\% CI, 76.9-98.2), respectively. The specificity of GMS staining, PCR on BAL fluid, and PCR on sputum was $100 \%(95 \%$ CI, 90.3-100), 86.1\% (95\% CI, 70.5-95.3), and 86.1\% (95\% CI, 70.5-95.3), respectively (Table 4).

\section{Diagnostic utility of serum cfDNA PCR}

When using defined diagnosis criteria, serum cfDNA PCR was positive in 14 patients. The sensitivity of serum cfDNA PCR was $77.8 \%$ (95\% CI, 52.4-93.6). There was no significant difference in comparison with BAL fluid PCR $(P=0.134)$ and sputum PCR $(P=0.249)$. However, the specificity of serum cfDNA PCR $(79.3 \%$, 95\% CI, 65.9-89.2) was higher than was that using both BAL fluid PCR $(P=0.009)$ and sputum PCR $(P=0.039)$.

When using clinical diagnosis criteria, serum cfDNA PCR was positive in 24 patients. The sensitivity of serum cfDNA PCR $(68.6 \%, 95 \% \mathrm{CI}, 50.7-83.1)$ was lower than was that using BAL fluid PCR $(P=0.004)$ and sputum PCR $(P=0.043)$. The specificity of serum cfDNA PCR (97.2\%, 95\% CI, 85.5-99.9) showed no significant difference with BAL fluid PCR $(P=0.221)$ and sputum PCR $(P=0.221)$, although there was a higher trend.

\section{Diagnostic utility of combined serum efDNA and sputum PCR}

The sensitivity and specificity of combined PCR on sputum and serum testing among 71 patients are summarized in Table 4. The combination of positive sputum AND positive serum criteria yielded a high specificity $(100 \%, 95 \%$ CI, 90.3-100) with a sensitivity, positive predictive value (PPV), and negative predictive value (NPV) of $62.9 \%$ (95\% CI, 44.9-78.5), 100\% and $73.5 \%$, respectively. The combination of positive sputum OR positive serum had a high sensitivity $(97.1 \%, 95 \%$ CI, 85.1-99.9) with a specificity, PPV, and NPV of $83.3 \%$ (95\% CI, 67.2-93.6), $85.0 \%$ and $96.8 \%$, respectively.

\section{Study summary of serum DNA in the diagnosis of PCP}

In our study, we searched the papers related to serum DNA detection in the diagnosis of PCP [13-20]. We found that the serum quantity, DNA extraction methods, PCR methods, PCR target and the standard to define PCP diagnosis were quite different among these studies (Table 5). As a result, the diagnostic sensitivities ranged from $0 \%$ to $100 \%$, while the diagnostic specificities ranged from $86.4 \%$ to $100 \%$. Regardless of the differences in these studies, the pooled sensitivity and specificity of serum DNA detection were 78/141 (55.3\%, 95\% CI, 
46.7-63.7) and 147/150 (98.0\%, 95\% CI, 94.3-99.6), respectively.

\section{DISCUSSION}

PCP is one of the most common pulmonary infection pathogens in immunocompromised patients. Laboratory methods for the diagnosis of PCP include etiological and molecular methods. Staining methods, including microscopy of the BAL fluid, sputum, or oropharyngeal wash, are the simplest methods used to confirm the diagnosis of PCP. However, the greatest disadvantage of the staining method is its low sensitivity $[8,21]$. In our study, the sensitivity of staining is only $51.4 \%$, partly due to the low Pneumocystis burden in non-HIV-infected patients [8] and the lack of experience of the observer and bronchoscopy operator. The low sensitivity of GMS staining resulted in a relatively small number of defined PCP cases in our study, thus leading to the low specificity of PCR when using GMS staining the gold standard.
Our results of PCR on BAL fluid and sputum show a high sensitivity $(97.1 \%$ and $91.4 \%$, respectively), which is consistent with other studies [22-24]. The specificity of PCR on BAL fluid and sputum are both $86.1 \%$ in our study, possibly due either to the presence of colonization of Pneumocystis in chronic lung disease patients $[23,25,26]$ or to the presence of dead organisms. Considering that BAL fluid and sputum samples are difficult to obtain in some PCP patients, such as critically ill and those with a non-productive cough, alongside the unsatisfying specificity of PCR on BAL fluid and sputum, PCR detection on different blood compartments has been developed as a noninvasive procedure to improve the diagnosis of PCP [27].

cfDNA is the fragments of DNA found extracellularly in different body fluids, mainly in circulating blood. It has been known for a few years that cfDNA can be used for diagnosing cancer, pregnancy associated complications, and infectious diseases, such as Plasmodium, Trypanosoma, Leishmania, Schistosoma, and Wuchereria spp. infections [12, 28, 29]. In studies

\section{5 consenting immunocompromised patients with suspected PCP such as}

fever, cough, dyspnea, or GGO on CT scans

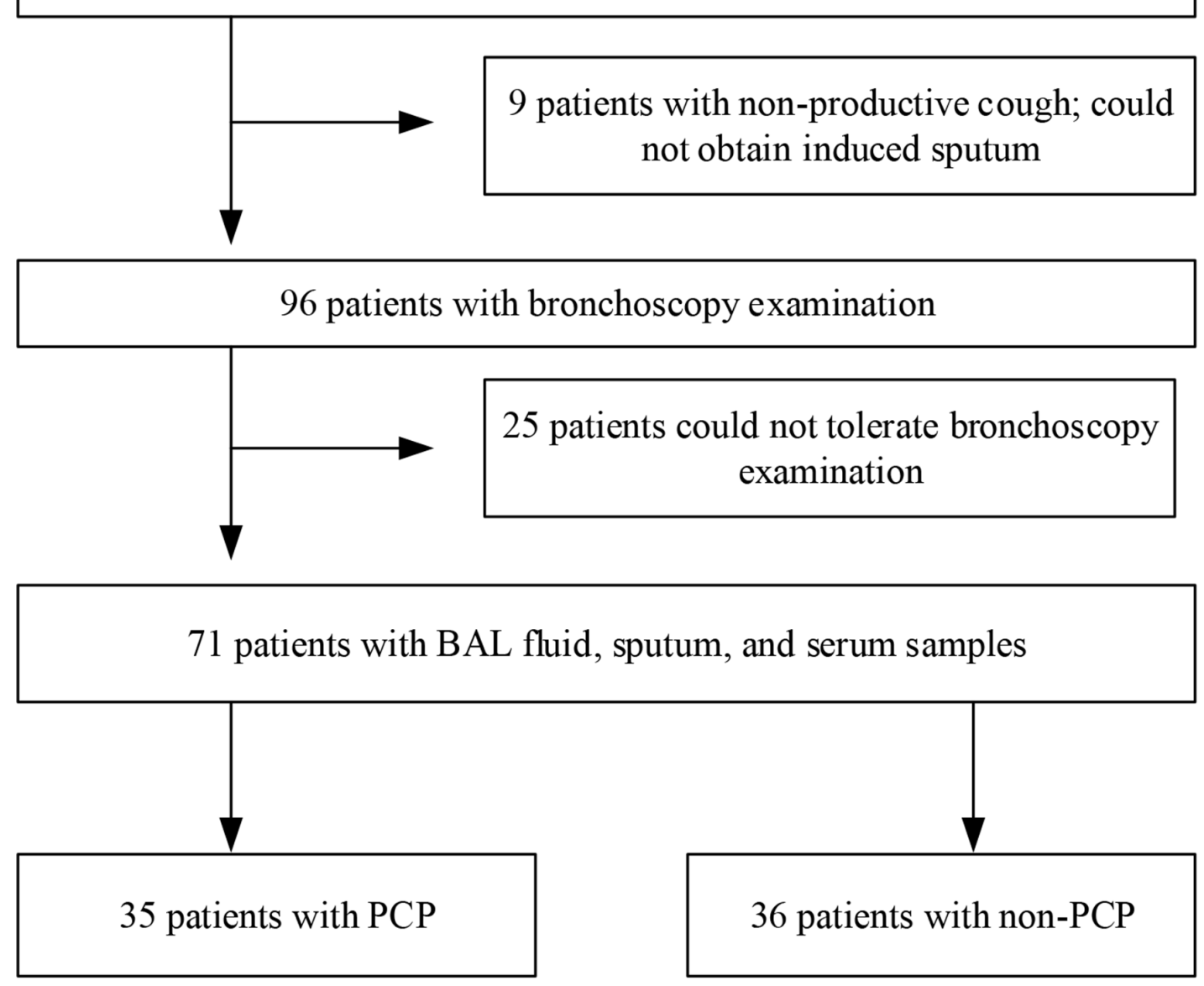

Figure 1: The screening and enrollment process of the study subjects. 
Table 1: Demographic and baseline cinical characteristics of enrolled patients with immunocompromised diseases

\begin{tabular}{|c|c|c|c|c|}
\hline Clinical characteristics & Total $(n=71)$ & $\operatorname{PCP}(n=35)$ & Non-PCP $(n=36)$ & $P$ value \\
\hline $\operatorname{Age}^{\dagger}$ & $51.7 \pm 14.4$ & $54.5 \pm 13.7$ & $48.9 \pm 14.7$ & 0.150 \\
\hline Male & $50(70.4 \%)$ & $24(68.6 \%)$ & $26(72.2 \%)$ & 0.736 \\
\hline \multicolumn{5}{|l|}{ Underlying diseases } \\
\hline Transplantation & $22(31.0 \%)$ & $15(42.9 \%)$ & $7(19.4 \%)$ & 0.033 \\
\hline Liver transplantation & $5(7.0 \%)$ & $3(8.6 \%)$ & $2(5.6 \%)$ & 0.974 \\
\hline Kidney transplantation & $17(23.9 \%)$ & $12(34.3 \%)$ & $5(13.9 \%)$ & 0.044 \\
\hline Malignancies & $14(19.7 \%)$ & $3(8.6 \%)$ & $11(30.6 \%)$ & 0.020 \\
\hline Leukemia & $3(4.2 \%)$ & $1(2.9 \%)$ & $2(5.6 \%)$ & 0.980 \\
\hline Lymphoma & $2(2.8 \%)$ & $0(0 \%)$ & $2(5.6 \%)$ & 0.493 \\
\hline Solid tumor & $9(12.7 \%)$ & $2(5.7 \%)$ & $7(19.4 \%)$ & 0.167 \\
\hline Immunosuppressed diseases & $35(49.3 \%)$ & $17(48.6 \%)$ & $18(50.0 \%)$ & 0.904 \\
\hline Chronic kidney disease & $13(18.3 \%)$ & $9(25.7 \%)$ & $4(11.1 \%)$ & 0.112 \\
\hline Interstitial pneumonia & $2(2.8 \%)$ & $1(2.9 \%)$ & $1(2.8 \%)$ & 1.000 \\
\hline Autoimmune diseases & $20(28.2 \%)$ & $7(20.0 \%)$ & $13(36.1 \%)$ & 0.131 \\
\hline \multicolumn{5}{|l|}{ Symptoms } \\
\hline Dyspnea & $56(78.9 \%)$ & $30(85.7 \%)$ & $26(72.2 \%)$ & 0.164 \\
\hline Cough & $62(87.3 \%)$ & $29(82.9 \%)$ & $33(91.7 \%)$ & 0.448 \\
\hline Sputum & $35(49.3 \%)$ & $13(37.1 \%)$ & $22(61.1 \%)$ & 0.043 \\
\hline Fever & $65(91.5 \%)$ & $32(91.4 \%)$ & $33(91.7 \%)$ & 0.696 \\
\hline GGO & $44(62.0 \%)$ & $30(85.7 \%)$ & $14(38.9 \%)$ & $<0.001$ \\
\hline
\end{tabular}

Values are presented as number (\%).

${ }^{\dagger}$ Values are presented as mean \pm standard deviation.

Table 2: Diagnostic performance of PCR in defined PCP patients

\begin{tabular}{lccc}
\hline & GMS staining $+(\boldsymbol{n}=\mathbf{1 8})$ & GMS staining $-(\boldsymbol{n}=\mathbf{5 3})$ & Total $(\boldsymbol{n}=\mathbf{7 1})$ \\
\hline BAL fluid PCR + & 18 & 21 & 39 \\
BAL fluid PCR - & 0 & 32 & 32 \\
& & & 37 \\
Sputum PCR + & 17 & 20 & 34 \\
Sputum PCR - & 1 & 33 & 25 \\
Serum PCR + & 14 & & 46 \\
Serum PCR - & 4 & 11 & 42 \\
\hline
\end{tabular}

Table 3: Diagnostic performance of GMS staining and PCR in clinical PCP patients

\begin{tabular}{lccc}
\hline & Clinical PCP $(\boldsymbol{n}=\mathbf{3 5})$ & Non-PCP $(\boldsymbol{n}=\mathbf{3 6})$ & Total $(\boldsymbol{n}=\mathbf{7 1})$ \\
\hline GMS staining + & 18 & 0 & 18 \\
GMS staining - & 17 & 36 & 53 \\
BAL fluid PCR + & 34 & 5 & 39 \\
BAL fluid PCR - & 1 & 31 & 32 \\
Sputum PCR + & 32 & 5 & 37 \\
Sputum PCR - & 3 & 31 & 34 \\
& & & \\
Serum PCR + & 24 & 1 & 25 \\
Serum PCR - & 11 & 35 & 46 \\
\hline
\end{tabular}


Table 4: Diagnostic performance of GMS staining, BAL fluid PCR, sputum PCR, serum PCR, and the combinations of sputum PCR and serum PCR for PCP diagnosis

\begin{tabular}{ccccc}
\hline Test & Sen (\%) 95\% CI & Spe (\%) 95\% CI & PPV (\%) & NPV (\%) \\
\hline GMS staining & $51.4(34.0-68.6)$ & $100(90.3-100)$ & 100 & 67.9 \\
BAL fluid PCR & $97.1(85.1-99.9)$ & $86.1(70.5-95.3)$ & 87.2 & 96.9 \\
Sputum PCR & $91.4(76.9-98.2)$ & $86.1(70.5-95.3)$ & 86.5 & 91.2 \\
$\quad$ Serum PCR & $68.6(50.7-83.1)$ & $97.2(85.5-99.9)$ & 96.0 & 76.1 \\
$\quad$ Sputum PCR & & & & \\
AND serum PCR & $62.9(44.9-78.5)$ & $100(90.3-100)$ & 100 & 73.5 \\
Sputum PCR & & & 85.0 & 96.8 \\
OR serum PCR & $97.1(85.1-99.9)$ & $83.3(67.2-93.6)$ &
\end{tabular}

Table 5: Study summary of serum DNA in PCP diagnosis

\begin{tabular}{cccccc}
\hline Year & PCR method & PCR target & Sensitivity (\%) & Specificity (\%) & Reference \\
\hline 1992 & C-PCR & DHFR & $12 / 14(85.7)$ & $6 / 6(100)$ & {$[13]$} \\
2012 & qPCR & mt LSU rRNA & $9 / 10(90.0)$ & $60 / 60(100)$ & {$[14]$} \\
1998 & N-PCR & ITSs & $10 / 14(71.4)$ & $26 / 26(100)$ & {$[15]$} \\
1996 & N-PCR & mt LSU rRNA & $0 / 15(0)$ & - & {$[16]$} \\
1996 & C-PCR & 5S rRNA & $10 / 10(100)$ & - & {$[17]$} \\
1995 & N-PCR & ITSs & $27 / 27(100)$ & $18 / 18(100)$ & {$[18]$} \\
1997 & DHFR & $2 / 20(10.0)$ & $18 / 18(100)$ & \\
1991 & C-PCR & mt LSU rRNA & $1 / 13(7.7)$ & $19 / 22(86.4)$ & {$[19]$} \\
\hline
\end{tabular}

Abbreviations: C-PCR, conventional PCR; N-PCR, nested PCR; DHFR, dihydrofolate reductase; ITSs, internal transcribed spacers.

related to parasite infections, cfDNA PCR has a relatively low diagnostic sensitivity, mainly due to the inadequacy of DNA extraction methods, which leads to a reduction of substrate content in PCR assays [12]. In our study, when using GMS staining as the gold standard, the sensitivity of serum cfDNA PCR was no different to that of BAL fluid PCR and sputum PCR, while the specificity was much higher. When using clinical diagnosis of PCP as diagnostic criteria, the serum cfDNA PCR showed high specificity and PPV, which were both superior to PCR on BAL fluid and sputum. According to the above evidence, serum cfDNA PCR is a valuable PCP diagnostic method.

According to the previous studies, the diagnostic performance of PCR on serum DNA has shown conflicting results, with a sensitivity ranging from $0-100 \%[27,30]$. This might be related both to the serum quantities used for DNA extraction and to technical variations, including DNA extraction methods, PCR methods, and targets for detecting Pneumocystis. In those studies, Proteinase K-phenol-chloroform was the main serum DNA extraction method. However, in our study, we chose magnetic bead methods, which is an efficient method in serum cfDNA extraction. In addition, different Pneumocystis primers may affect the results of cfDNA PCR. We used the Pneumocystis heat shock protein (HSP) 70 gene as the target gene, while most of the previous studies used Pneumocystis mitochondrial large subunit ribosome RNA (mt LSU rRNA) gene in Pneumocystis detection. As proved by Hugett et al., the HSP70 gene has higher sensitivity and specificity in Pneumocystis detection than does the Pneumocystis mt LSU rRNA gene [31].

The combined specificity of "positive sputum AND positive serum" PCR is $100 \%$, which is superior to the specificity of BAL fluid PCR, and this approach could be used to reduce the incidence of the false positive rate when used in clinical criteria. The combined sensitivity of "positive sputum OR positive serum" is as high as is the sensitivity of BAL fluid PCR detection. Consequently, to reduce the misdiagnosis rate, the combination of "positive sputum OR positive serum" should be used in patients who are highly suspected of having PCP with bronchoscopy intolerance. 
There are some limitations in this study. First, as it is a single center study with a relatively small enrolled patient number, this may cause a selection bias. Although this could not be avoided, future studies will focus on validating our results in a multicenter setting. Second, since our aim is to compare the sensitivity and specificity of PCR using BAL fluid, sputum, and serum cfDNA in PCP diagnosis, the PCR test on Pneumocystis in this study was qualitative rather than quantitative, which is responsible for the failure in investigating the consistency of the Pneumocystis load in BAL fluid/sputum with it in serum. Third, cfDNA is unstable in the circulating blood and will be degraded by nucleases. According to a published study, the half-life of fetal cfDNA in the maternal blood circulation is around 16 minutes [32]. Similarly, a study by M. Fleischhacker et al. has shown that the half-life of circulating tumor DNA is only from 15 minutes to several hours [33]. For these reasons, we theorized that a rapid detection of the sample may improve the diagnostic performance.

In conclusion, PCR on both BAL fluid and sputum is highly sensitive in PCP diagnosis, while GMS staining and serum PCR are highly specific. In critically ill patients who cannot tolerate bronchoscopy, the combination of PCR positive on serum or positive on sputum implies a very high probability of PCP.

\section{MATERIALS AND METHODS}

\section{Study population and sample collection}

A prospective study that enrolled non-HIV immunocompromised patients suspected of PCP was conducted in Beijing Chao-Yang Hospital from January 2015 to November 2016. According to our published study [34], the immunocompromised status meets one of the following factors: treatment with immunosuppressants during the past 90 days; receipt of an allogeneic stem cell or solid organ transplant; chronic underlying disease or major operations; prolonged use of corticosteroids; and inherited severe immunodeficiency. Suspected PCP was defined as either having clinical symptoms such as cough, fever, and dyspnea, or having ground grass opacity (GGO) in high resolution CT scans. The study was approved by the Institutional Review Board of Beijing Chao-Yang Hospital, and written informed consent was obtained from all participants. Patients who either could not undergo bronchoscopy or failed to obtain sputum samples were excluded from the study. Demographic and medical data were collected from the enrolled patients. Peripheral blood, sputum (spontaneous or induced sputum), and BAL fluid under bronchoscopy were also collected from them. The sputum samples for PCR were collected more than once in the enrolled patients, but only the first result of sputum PCR was evaluated for its diagnostic value.

\section{Diagnosis of PCP}

The following criteria were used for the diagnosis of PCP: (1) BAL fluid or sputum GMS staining yielded Pneumocysits cysts. (2) BAL fluid or sputum PCR yielded positive results in two replicates. The defined diagnosis was defined to meet the criteria (1). The clinical diagnosis was defined to meet the criteria (2).

\section{Samples processing}

BAL fluid samples were centrifuged at 1,600 $\mathrm{g}$ for $5 \mathrm{~min}$ at $4^{\circ} \mathrm{C}$. To avoid non-specific inhibition, no mucolytic agent was used for these samples. Sputum samples were first treated with equal volumes of pancreatin at $37^{\circ} \mathrm{C}$ for $15 \mathrm{~min}$ and then centrifuged at $1,600 \mathrm{~g}$ for 10 min. The resulting pellet was washed twice with phosphate buffer saline (PBS) and resuspended in $1 \mathrm{ml}$ of PBS. Blood samples were centrifuged at $6,000 \mathrm{~g}$ for $10 \mathrm{~min}$ at $4^{\circ} \mathrm{C}$. The serum was obtained and centrifuged at $16,000 \mathrm{~g}$ for another $10 \mathrm{~min}$ at $4^{\circ} \mathrm{C}$.

\section{Staining for Pneumocystis jirovecii}

A portion of resuspended pellet of sputum was used to make a smear for GMS staining, according to the manufacturer's instructions (Baso, Zhuhai, China). The stained smears were visualized under a microscope for Pneumocystis cysts.

\section{DNA extraction and $q P C R$}

For BAL fluid and sputum samples, DNA was extracted from the resuspended pellet using a QIAamp DNA Mini kit (Qiagen, Hamburg, Germany), according to the manufacturer's instructions. For serum samples, cfDNA was extracted using the MagMAX ${ }^{\mathrm{TM}}$ Cell-Free DNA Isolation Kit (Thermo Fisher Scientific, Massachusetts, US), according to the instructions provided in the kit. DNA and cfDNA of a $151 \mathrm{bp}$ fragment of the Pneumocystis jirovecii HSP70 gene were detected by qPCR. The forward primer was 5'-GCA GGA TTG AAT GTT TTA C-3', the reverse primer was 5'-CCT CTT CGA TAG TTA ATA ACG-3', and the TaqMan probe was 5'-FAM-CAA TGA ACC TAC AGC AGC AGC C-MGBNFQ-3'.

\section{Statistics analysis}

Comparison of two independent samples was performed using a Mann-Whitney $U$ test and chi-square tests, and a $P$ value of less than 0.05 was considered statistically significant. The results of the diagnostic tests were described as sensitivity, specificity, PPV, and NPV. All analyses were calculated using the software 19.0 (SPSS Inc., Chicago, US) and MedCalc (MedCalc Software, Ostend, Belgium). 


\section{Author contributions}

Z. H. T. serves as the guarantor of the manuscripts and takes responsibility for the integrity of the work as a whole, from study design to publication. D. W. and Y. H. contributed to the data collection, data analysis and the writing of the manuscript. T. L.and H.M.R. contributed to the conduct of qPCR and GMS staining.

\section{CONFLICTS OF INTEREST}

\section{The authors declare no conflicts of interest.}

\section{FUNDING}

This work was funded by the National Natural Science Foundation of China (NO. 81570003 and NO.81370102), in part by a grant from Beijing Natural Science Foundation Program and Scientific Research Key Program of Beijing Municipal Commission of Education (KZ20140025026), in part by a grant from the development of GCP evaluation system in the field of respiratory diseases with advanced technology (2014ZX09303302), and in part by a grant from the Specialized Research Fund for the Doctoral Program of Higher Education (20131107110003).

\section{REFERENCES}

1. Carmona EM, Limper AH. Update on the diagnosis and treatment of Pneumocystis pneumonia. Ther Adv Respir Dis. 2011; 5:41-59.

2. Calderon EJ, Gutierrez-Rivero S, Durand-Joly I, Dei-Cas E. Pneumocystis infection in humans: diagnosis and treatment. Expert Rev Anti Infect Ther. 2010; 8:683-701.

3. Thomas CJ, Limper AH. Pneumocystis pneumonia: clinical presentation and diagnosis in patients with and without acquired immune deficiency syndrome. Semin Respir Infect. 1998; 13:289-295.

4. Kovacs JA, Masur H. Evolving health effects of Pneumocystis: one hundred years of progress in diagnosis and treatment. JAMA. 2009; 301:2578-2585.

5. Cooley L, Dendle C, Wolf J, Teh BW, Chen SC, Boutlis C, Thursky KA. Consensus guidelines for diagnosis, prophylaxis and management of Pneumocystis jirovecii pneumonia in patients with haematological and solid malignancies, 2014. Intern Med J. 2014; 44:1350-1363.

6. Monnet X, Vidal-Petiot E, Osman D, Hamzaoui O, Durrbach A, Goujard C, Miceli C, Bouree P, Richard C. Critical care management and outcome of severe Pneumocystis pneumonia in patients with and without HIV infection. Crit Care. 2008; 12:R28.
7. Mori S, Sugimoto M. Pneumocystis jirovecii infection: an emerging threat to patients with rheumatoid arthritis. Rheumatology (Oxford). 2012; 51:2120-2130.

8. Jiancheng W, Minjun H, Yi-jun A, Lan S, Zengzhu G, Jianrong S, Xixiong K. Screening Pneumocystis carinii pneumonia in non-HIV-infected immunocompromised patients using polymerase chain reaction. Diagn Microbiol Infect Dis. 2009; 64:396-401.

9. Jarboui MA, Sellami A, Sellami H, Cheikhrouhou F, Makni F, Ben AN, Ben JM, Ayadi A. Molecular diagnosis of Pneumocystis jirovecii pneumonia in immunocompromised patients. Mycoses. 2010; 53:329-233.

10. Durand-Joly I, Chabe M, Soula F, Delhaes L, Camus D, DeiCas E. Molecular diagnosis of Pneumocystis pneumonia. FEMS Immunol Med Microbiol. 2005; 45:405-410.

11. Palladino S, Kay I, Fonte R, Flexman J. Use of real-time PCR and the LightCycler system for the rapid detection of Pneumocystis carinii in respiratory specimens. Diagn Microbiol Infect Dis. 2001; 39:233-236.

12. Weerakoon KG, McManus DP. Cell-Free DNA as a Diagnostic Tool for Human Parasitic Infections. Trends Parasitol. 2016; 32:378-391.

13. Schluger N, Godwin T, Sepkowitz K, Armstrong D, Bernard E, Rifkin M, Cerami A, Bucala R. Application of DNA amplification to pneumocystosis: presence of serum Pneumocystis carinii DNA during human and experimentally induced Pneumocystis carinii pneumonia. J Exp Med. 1992; 176:1327-1333.

14. Costa JM, Botterel F, Cabaret O, Foulet F, Cordonnier C, Bretagne $\mathrm{S}$. Association between circulating DNA, serum $(1 \rightarrow 3)$-beta-D-glucan, and pulmonary fungal burden in Pneumocystis pneumonia. Clin Infect Dis. 2012; 55:e5-8.

15. Atzori C, Agostoni F, Angeli E, Mainini A, Orlando G, Cargnel A. Combined use of blood and oropharyngeal samples for noninvasive diagnosis of Pneumocystis carinii pneumonia using the polymerase chain reaction. Eur J Clin Microbiol Infect Dis. 1998; 17:241-246.

16. Tamburrini E, Mencarini P, Visconti E, Zolfo M, De Luca A, Siracusano A, Ortona E, Wakefield AE. Detection of Pneumocystis carinii DNA in blood by PCR is not of value for diagnosis of P. carinii pneumonia. J Clin Microbiol. 1996; 34:1586-1588.

17. Miyawaki H, Fujita J, Hojo S, Harada M, Yamaji Y, Suguri S, Takahara J. Detection of Pneumocystis carinii sequences in serum by polymerase chain reaction. Respir Med. 1996; 90:153-157.

18. Atzori C, Lu JJ, Jiang B, Bartlett MS, Orlando G, Queener SF, Smith JW, Cargnel A, Lee CH. Diagnosis of Pneumocystis carinii pneumonia in AIDS patients by using polymerase chain reactions on serum specimens. J Infect Dis. 1995; 172:1623-1626.

19. Wagner D, Koniger J, Kern WV, Kern P. Serum PCR of Pneumocystis carinii DNA in immunocompromised patients. Scand J Infect Dis. 1997; 29:159-164. 
20. Schluger N, Sepkowitz K, Armstrong D, Bernard E, Rifkin M, Cerami A, Bucala R. Detection of Pneumocystis carinii in serum of AIDS patients with Pneumocystis pneumonia by the polymerase chain reaction. J Protozool. 1991; 38:240S-242S.

21. Tasaka S, Tokuda H. Pneumocystis jirovecii pneumonia in non-HIV-infected patients in the era of novel immunosuppressive therapies. J Infect Chemother. 2012; 18:793-806.

22. Chawla K, Martena S, Gurung B, Mukhopadhyay C, Varghese GK, Bairy I. Role of PCR for diagnosing Pneumocystis jirovecii pneumonia in HIV-infected individuals in a tertiary care hospital in India. Indian J Pathol Microbiol. 2011; 54:326-329.

23. Flori P, Bellete B, Durand F, Raberin H, Cazorla C, Hafid J, Lucht F, Sung RT. Comparison between real-time PCR, conventional PCR and different staining techniques for diagnosing Pneumocystis jirovecii pneumonia from bronchoalveolar lavage specimens. J Med Microbiol. 2004; 53:603-607.

24. Alvarez-Martínez MJ, Miró JM, Valls ME, Moreno A, Rivas PV, Solé M, Benito N, Domingo P, Muñoz C, Rivera E, Zar HJ, Wissmann G, Diehl AR, et al, and Spanish PCP Working Group. Sensitivity and specificity of nested and real-time PCR for the detection of Pneumocystis jiroveci in clinical specimens. Diagn Microbiol Infect Dis. 2006; 56:153-60.

25. Wang DD, Zheng MQ, Zhang N, An CL. Investigation of Pneumocystis jirovecii colonization in patients with chronic pulmonary diseases in the People's Republic of China. Int J Chron Obstruct Pulmon Dis. 2015; 10:2079-2085.

26. Ribes JA, Limper AH, Espy MJ, Smith TF. PCR detection of Pneumocystis carinii in bronchoalveolar lavage specimens: analysis of sensitivity and specificity. J Clin Microbiol. 1997; 35:830-835.
27. Frealle E, Gantois N, Aliouat-Denis CM, Leroy S, Zawadzki C, Perkhofer S, Aliouat EM, Dei-Cas E. Comparison of different blood compartments for the detection of circulating DNA using a rat model of Pneumocystis pneumonia. Med Mycol. 2015; 53:754-759.

28. Wagner J. Free DNA - new potential analyte in clinical laboratory diagnostics? Biochem Med (Zagreb). 2012; 22:24-38.

29. Yu J, Gu G, Ju S. Recent advances in clinical applications of circulating cell-free DNA integrity. Lab Med. 2014; 45:6-11.

30. van Halsema C, Johnson L, Baxter J, Douthwaite S, Clowes Y, Guiver M, Ustianowski A. Short Communication: Diagnosis of Pneumocystis jirovecii Pneumonia by Detection of DNA in Blood and Oropharyngeal Wash, Compared with Sputum. AIDS Res Hum Retroviruses. 2016; 32:463-466.

31. Huggett JF, Taylor MS, Kocjan G, Evans HE, MorrisJones S, Gant V, Novak T, Costello AM, Zumla A, Miller RF. Development and evaluation of a real-time PCR assay for detection of Pneumocystis jirovecii DNA in bronchoalveolar lavage fluid of HIV-infected patients. Thorax. 2008; 63:154-159.

32. Lo YM, Zhang J, Leung TN, Lau TK, Chang AM, Hjelm NM. Rapid clearance of fetal DNA from maternal plasma. Am J Hum Genet. 1999; 64:218-224.

33. Fleischhacker M, Schmidt B. Circulating nucleic acids (CNAs) and cancer-A survey. Biochim Biophys Acta. 2007; 1775:181-232.

34. Guo F, Chen Y, Yang SL, Xia H, Li XW, Tong ZH. Pneumocystis pneumonia in HIV-infected and immunocompromised non-HIV infected patients: a retrospective study of two centers in China. PLoS One. 2014; 9:e101943. 